\title{
A boundary-crossing approach to support students' integration of statistical and work-related knowledge
}

\author{
Arthur Bakker • Sanne F. Akkerman
}

Published online: 31 October 2013

(C) The Author(s) 2013. This article is published with open access at Springerlink.com

\begin{abstract}
Vocational students and beginning professionals typically find it hard to integrate the mathematics and statistics that they have learned at school with work-related knowledge. To explore how such an integration process could be supported, we conducted an intervention in secondary vocational laboratory education. Our boundary-crossing approach was informed by the literature on boundary crossing and accompanying learning mechanisms (e.g., reflection in the form of perspective making and taking, and transformation in the form of hybridization). We hypothesized that reflection, as making and taking perspectives on school-taught and work-related knowledge, could lead to transformation, i.e., help students integrate these types of knowledge into a hybridized whole. Data collection included video and audio recordings of five 1-h meetings with three students, the data from their research projects, and interviews with the teacher and two workplace supervisors. The analysis of the students' reasoning during the meetings revealed that their level of integrating school-taught statistics and work-related knowledge increased significantly and with a medium effect size. This suggests that a boundary-crossing approach can support students in integrating school-taught and workrelated knowledge.
\end{abstract}

Keywords Boundary object $\cdot$ Internship $\cdot$ Knowledge integration $\cdot$ Reflection $\cdot$ Vocational mathematics $\cdot$ Workplace mathematics

Discrepancies between mathematical knowledge as taught at school and as used out-of-school have been found for many years (cf. Lave, 1988; Nunes, Schliemann, \& Carraher, 1993). It is also known that statistics, as taught at school, is quite different from what is typically used in workplaces (e.g., Bakker, Kent, Derry, Noss, \& Hoyles, 2008). Given these differences, one of the key challenges in mathematics and statistics education is to help people use abstract

This manuscript has been written for the special issue titled Vocational Knowledge.

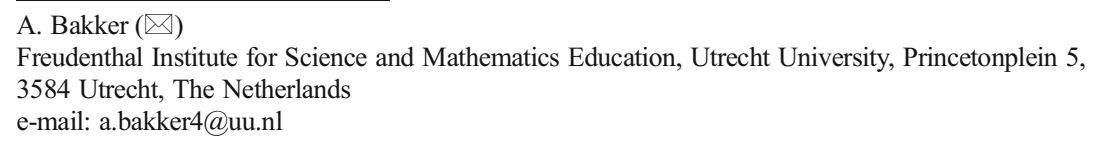

S. F. Akkerman

Faculty of Social and Behavioral Sciences, Utrecht University, Utrecht, The Netherlands 
mathematical and statistical knowledge in out-of-school situations such as work (FitzSimons \& Coben, 2009).

For a long time, this challenge has been conceptualized as a problem of transfer. Transfer is mostly considered the application of some general principle by a person in a new situation when confronted with a task. As many scholars have argued, however, adopting a transfer perspective has its limitations (e.g., Lave, 1988; Nunes et al., 1993). The concept of transfer is mostly used for unidirectional processes and oriented towards individuals performing tasks. In sociocultural traditions (e.g., Tuomi-Gröhn \& Engeström, 2003), the broader metaphor of boundary crossing (Suchman, 1994) has been proposed to capture the often more complex efforts by people who move not only forth but also back; boundary crossing is therefore bidirectional and dynamic. Moreover, it is oriented towards both the personal and the collective. The concept of boundary crossing thus draws attention to a wider range of relevant processes involved in integrating different types of knowledge to be learned and used in different contexts.

In recent years, some descriptive workplace research in mathematics education has shown how boundary-crossing processes take place in the workplace (Kent, Noss, Guile, Hoyles \& Bakker 2007; Roth, 2012). Given our overall project aim to develop a boundary-crossing approach there was little interventionist research to build upon. There has been some interventionist research in workplaces stimulating boundary crossing (e.g., Hoyles, Noss, Kent, \& Bakker, 2010; Williams \& Wake, 2007). At the university level, Hahn (2011) developed a "pedagogical device" for business school students to support them in linking their academic knowledge with their work experience. This pedagogical device was a four-step learning activity based on exploratory data analysis and inspired by an authentic workplace situation: based on statistical information, students had to choose which of the three hypothetical sales areas they preferred to manage.

In vocational education research, however, there is even less to inform an intervention. In a previous study, we designed a computer tool intended to foster vocational students' proportional reasoning in relation to work tasks such as the dilution of chemicals (Bakker, Groenveld, Wijers, Akkerman, \& Gravemeijer, 2012). This computer tool was characterized as a Janus-headed (double-faced) tool, assisting students in integrating school-taught mathematical knowledge and work-related laboratory knowledge. Vocational education is an interesting area to investigate further because the boundary crossing between school and work - typically out of the sight of researchers - can be studied in vivo here. Moreover, the aforementioned challenge of helping students to use mathematics in concrete situations is most pertinent here. As Wedege (1999) noted, vocational students often do not see the point of learning mathematics, whereas the need to use it is often obvious from an expert perspective (e.g., Bakker, Wijers, Jonker, \& Akkerman, 2011). The purpose of this article is to provide insight into how vocational students can be supported to integrate the statistical knowledge they have learned mainly at school with work-related knowledge they develop mainly during internships through what we call a boundary-crossing approach.

\section{Boundary crossing for integration}

The aforementioned discrepancies between school-taught mathematics and statistics and workrelated knowledge can be conceptualized as boundaries. In our review study, we defined boundaries as "sociocultural differences that give rise to discontinuities in action and interaction" (Akkerman \& Bakker, 2011, p. 139). The challenge then is how to help students cross such boundaries, in our case to integrate different types of knowledge typically 
developed in different practices. Not being able to use school-taught knowledge in the workplace is an example of discontinuity. We define boundary crossing as the efforts by individuals or groups at boundaries to establish or restore continuity in action or interaction across practices (cf. Akkerman, Bruining, \& Van den Eijnden, unpublished; Bakker \& Akkerman, 2013). This includes "negotiating and combining ingredients from different contexts to achieve hybrid situations" (Engeström, Engeström, \& Kärkkäinen, 1995, p. 319).

This process can be facilitated by boundary objects, objects that "both inhabit several intersecting worlds and satisfy the informational requirements of each of them" (Star \& Griesemer, 1989, p. 393). In the context of vocational and higher education, we can think of portfolios (Meeus, Van Petegem, \& Van Looy, 2006) as boundary objects that help school mentors and workplace supervisors track students' developments. Yet, we should note that boundary objects can never displace interaction or collaboration. As Wenger (1998, p. 108) observed, boundary objects "are in fact the nexus of perspectives, and that it is often in the meeting of these perspectives that artifacts obtain their meanings."

As Engeström et al. (1995) pointed out, boundary crossing can lead to integration in terms of hybridity. In our study, we wanted to think through how such boundary crossing could be supported in vocational education. Our review study on boundary crossing revealed several learning mechanisms and processes that can be triggered at boundaries (Akkerman \& Bakker, 2011). In the current article, we focus on the learning mechanisms of reflection and transformation. The key processes of reflection are perspective making and perspective taking. Boland and Tenkasi (1995, p. 351) defined perspective making as "communication that strengthens the unique knowledge of a community" and perspective taking as "communication that improves its ability to take the knowledge of other communities into account." The learning mechanism of transformation can involve several processes, for example, confrontation and hybridization. Confrontation with differences can lead to the need of integrating knowledge types into a hybrid whole.

The majority of studies in our review focused on such processes at the level of practices or between individuals. We imagine that these processes can also take place within individuals, for example, when they look differently at school-taught statistics because of their participation in a workplace context as an intern, or take a fresh perspective on work-related knowledge because of their participation in a school-based statistics class. We hypothesize that in making and taking perspectives on how statistics is used at school and at work, students learn to integrate and thus transform their school-taught and work-related knowledge.

What would boundary crossing for integrating knowledge types look like in vocational mathematics education? Several researchers have explored the potential of boundary crossing in the workplace. Williams and Wake (2007) invited students of mathematics to visit workplaces with them and to discuss what they had seen, thus helping them to become aware of the differences between the mathematics of college and of work cultures. Communication about models supported a reflective process that enabled them to establish more continuity between school and work. Hoyles et al. (2010) studied how enhanced mathematical or statistical perspectives on work processes could improve production processes and communication with customers. In collaboration with manufacturing and financial companies, they developed an approach to creating mathematical learning opportunities along with what they called technology-enhanced boundary objects (TEBOs). TEBOs are reconfigurations of workplace artifacts designed to help employees understand the relevant mathematics or statistics behind these artifacts. They take the form of computer tools that combine mathematical and work-related ingredients so as to facilitate boundary crossing; for example, a spreadsheet with mortgage information (Bakker, Kent, Hoyles, \& Noss, 2011), or visual 
displays of statistical graphs used in industrial process improvement strategies (Bakker, Kent, Noss, \& Hoyles, 2009).

In this article, we apply the insights gained in workplace research to vocational education in schools. We focused on the school-based variant of Dutch senior secondary vocational education (MBO), where students are mostly between 16 and 22 years old. The first year is school-based, but there is a gradual shift to internship in the final year. Internship is defined here as work placement without a formal contract or salary. The day release program of the final year, when students come back to school 1 day per 2 weeks, is a particularly interesting place to study students' boundary crossing between school and work.

For operationalizing the extent to which students integrate these types of knowledge, we formulated two principles; namely that:

1. Involving both school-taught statistics and workplace-related knowledge in a statement or reasoning indicates a higher level of knowledge integration than involving either statistical or workplace-related knowledge.

2. Reasoning or explaining indicates a higher knowledge level than merely making a statement. A sign of reasoning or explanation is if students use if-then constructions or if cause-effect relationships are formulated.

The first principle is the direct consequence of valuing integration higher than demonstration of one type of knowledge. The second principle is in line with hierarchies of student understanding of particular statistical concepts (e.g., Reading \& Reid, 2004; Watson \& Moritz, 2000). To evaluate our boundary-crossing approach, we address the following research question: How, and to what extent, did students in a boundary-crossing approach learn to integrate statistical and work-related knowledge in their reasoning about work tasks?

\section{Methods}

We designed an intervention of five 1-h meetings following the aforementioned boundarycrossing approach. The design was also informed by ethnographic and survey research in laboratories and laboratory education (Akkerman \& Bakker, 2012; Bakker, Wijers, \& Akkerman, 2010) as well as by classroom observation, analysis of 31 student reports, and exploratory interviews with teachers in the vocational school in which we conducted the intervention.

\subsection{The participants}

The participants were three students (19 years old), one male, Ferdie, and two females, Sylvana and Petra (all names are pseudonyms), in their fourth and final year of the highest level (4) of the clinical chemistry variant of MBO laboratory education. The first author was their teacher for this intervention. Two supervisors from a hospital laboratory attended the third session; one was a clinical chemist (MSc), the other a managing laboratory technician (BSc).

\subsection{The setting and learning goals}

Method comparison is a common project for many students in clinical chemistry education, involving considerable use of statistics. By comparing a new method to an accurate old one, laboratories can check if the new method is as accurate as the old one. A reason for making such comparison is that the new method can be faster and cheaper (e.g., if done in their own 
hospital laboratory rather than in another). One important preparatory step is to test the stability of measurement machines and reproducibility of the measurement method, statistically expressed in terms of a standard deviation or coefficient of variation. The reason for such stability and reproducibility checks is that they are necessary for a reliable method comparison, the core of the students' projects. This core involves the pairwise comparison of patient blood in both machines, leading to paired data to be represented in a scatter plot (Fig. 1). Correlation and regression are applied to measure the degree of correlation (here, $R^{2}=0.9648$ ) and, more importantly, the slope of the regression line (here, 0.751 ).

From our ethnographic research and textbook analysis (e.g., Raadschelders \& den Rooijen, 2007) we knew that laboratory technicians typically think in terms of linearity, bias, stability, and reproducibility of measurements. They are thus concerned with whether measurements are accurate and stable. Hence, their primary concern is to avoid bias and variation. What is not clear for most students are the connections between such laboratory-based concepts on the one hand, and school-taught statistical concepts and techniques such as coefficient of variation, slope, correlation and regression on the other. Yet, these school-taught statistical concepts and techniques are necessary to measure linearity, bias, stability, and reproducibility:

- Stability and reproducibility can be estimated as a percentage based on the coefficient of variation (100\% times sample standard deviation divided by the sample mean).

- Linearity can be measured with the correlation coefficient, which should be close to 1.00 . The regression line is the line of best fit.

- The bias of a machine can be derived from the slope of the regression line, which should also be close to 1.00 , in combination with the intercept, which should be close to 0 .

- In machine validation, the intercept ideally is 0 , because if a particular substance is not present, both machines should measure 0 . However, if there is a bias, it may be a constant

Fig. 1 Comparison of the measurement of some protein by machines $\mathrm{A}$ and $\mathrm{B}$ in $\mathrm{mg} / \mathrm{L}$ (original data have been slightly adjusted for confidentiality reasons)

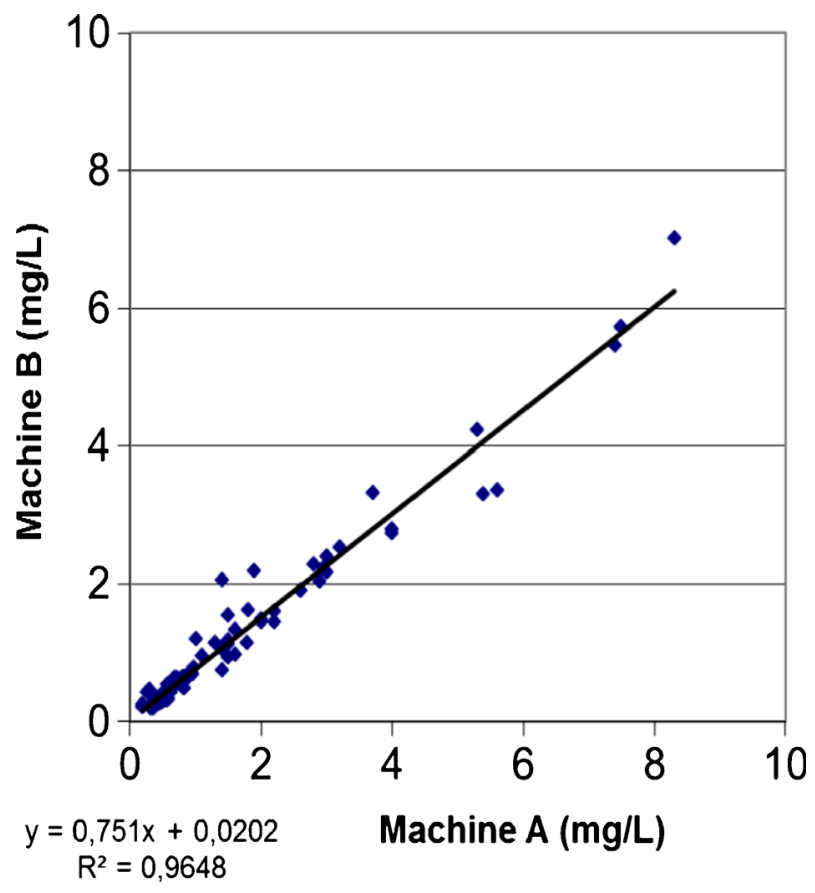


multiplicative factor (say*1.02) or else there may be a constant difference (say +0.2 ). In the former case, the intercept should be 0 , but in the latter case, not. This implies that technicians need to decide whether to choose, when using computer software such as Excel $^{\mathrm{TM}}$ spreadsheets, the option of the intercept being 0 .

The learning goal was that students would be able to make these connections and considerations, and use this knowledge in solving work tasks such as method comparison. An additional learning goal was that students would be able to reason scientifically about common dilemmas in dealing with practical problems. For example, what should the laboratory technician do if a machine is biased? Such choices involve considering a wide web of reasons (Bakker \& Derry, 2011), including not only statistical, practical, and clinical reasons, but also the possible consequences for medical specialists and patients as potential users of the results. Being responsive to these different types of reasons requires different types of knowledge. Our assumption was that supporting students in taking a school-based statistical perspective on method comparison and a work-related perspective on statistical techniques would help them integrate the various types of knowledge involved, and thus cross the boundaries between school-taught and work-related knowledge.

\subsection{The intervention}

The intervention capitalized on both boundary objects and students' boundary crossing. We first discuss the objects in our intervention and then how we stimulated students to cross boundaries.

In the meetings, we used the same software that was used in the students' laboratories at work: Excel ${ }^{\mathrm{TM}}$. We further handed out a report of a student's project of the previous school year, about comparing a new machine for measuring a concentration of a chemical substance with the old, reliable machine. We considered the report a boundary object because it served different functions in different communities. Initially, it was the end product of a student's project, at work in a hospital, where the results were useful to the laboratory (whether the new machine was reliable and stable enough), and it was graded at school, as part of the student's diploma requirements. We used the report (a) to give the following year's students an idea of what kind of project they may be doing in their own laboratories, (b) to discuss the statistics needed for such projects, (c) to stimulate students to ask questions, and (d) for teachers and supervisors to talk about their expectations of students. As such, we expected it to satisfy the needs of different intersecting worlds, and thus to be a boundary object.

To promote boundary crossing, we stimulated students to formulate questions at work and ask them at school, and vice versa. In addition, workplace supervisors were invited to the school for one meeting to answer students' questions and to tell them about how statistics is used in hospital laboratories. They discussed with the students what they thought was important about the statistics required for method comparison.

\subsection{Data collection}

In this study, the following data were collected. Pre-interviews with two teachers were conducted and audio-recorded. All classroom interaction during the meetings was videoand audio-recorded. A brief questionnaire on their school-taught statistical knowledge and how statistics was used at work was administered at the beginning of the first meeting and subsequently discussed with the students. Student work, including reports and presentations, was collected. All verbal interactions were transcribed verbatim. 


\subsection{Data analysis}

In the literature, we had not found operational definitions of the integration of school-taught knowledge, on the one hand, and work-related knowledge, on the other. Thus, no validated measurement scales seemed to be available for this purpose; hence, we needed to develop one ourselves in order to answer our research question. Based on the two aforementioned principles, we defined four levels, summarized in Table 1. Following the first principle, levels 3 and 4 are defined as higher than levels 1 and 2. Following the second principle, level 2 is considered higher than level 1, and level 4 higher than level 3.

The transcripts were divided into fragments that addressed one topic (on average about six turns about the same issue). This resulted in about 40 to 46 fragments per meeting, except in the third meeting when one supervisor talked at length about particular topics, which resulted in only 25 fragments (Table 2). We attributed codes (Table 1) to fragments of group interaction. Each of the fragments was given one code - determined by the highest level of statement or reasoning in that fragment, irrespective of which student made the statement or expressed the reasoning. We give one example for each code.

The first example (one turn from a fragment) stems from the first meeting:

Sylvana: I have not seen this in my current internship, but I have in my previous one.

This is considered a level 1 utterance because it is a statement about work-related knowledge only.

The second example stems from the second meeting:

Sylvana: If the results [of the new method] deviate too much [from the reliable old method] (...) then you cannot use the method, because then the patients' measurements are not all right. Only a specific deviation is allowed.

This utterance was considered reasoning (indicated by "if ... then" and "because") but using only work-related, non-statistical reasons (level 2). If she had shown understanding of the deviation earlier in the transcript in terms of a slope of the regression line, variation coefficient, or a standard deviation, then we would have coded it at level 4.

The third example stems from the fourth meeting:

Petra: I have asked it [at work]. They ask you to calibrate when two [measurements] are outside two SD [standard deviations] and one outside three SD. If it is not OK after calibration, calibrate again or call the company.

Here, she mentioned both work-related (the norm in her lab) and statistical elements (the two and three SD limits), but we coded this as a statement (level 3) rather than an example of

Table 1 Levels of knowledge integration used as codes in the data analysis

\section{Level Characterization}

1 Statement about something statistical-mathematical (school-taught) or work-related but without explanation or reasoning

2 Reasoning or explanation with only statistical-mathematical or only work-related (non-statistical) knowledge

3 Statement in which a statistical-mathematical fact and a work-related fact are combined

$4 \quad$ Reasoning with both statistical-mathematical and work-related knowledge 
Table 2 Numbers of codes for knowledge integration levels in each meeting

\begin{tabular}{|c|c|c|c|c|c|c|}
\hline & M 1 & M 2 & M 3 & M 4 & M 5 & Total \\
\hline Level 1 & 23 & 25 & 11 & 15 & 7 & 81 \\
\hline Level 2 & 20 & 13 & 6 & 4 & 14 & 57 \\
\hline Level 3 & 1 & 2 & 7 & 12 & 9 & 31 \\
\hline Level 4 & 1 & 5 & 1 & 9 & 16 & 32 \\
\hline Total & 45 & 45 & 25 & 40 & 46 & 201 \\
\hline
\end{tabular}

reasoning because she just reported workplace rules involving statistics without an explanation.

The fourth example shows interaction at level 4. It concerned the clinical meaning of outliers, a statistical concept for which the students had learned statistical tests (Dixon's Q test and Grubbs' test). The reference value of thrombosis indication was $0.50 \mathrm{mg} / \mathrm{L}$ of a particular protein, below which the patient most likely has no thrombosis. When talking about whether 1.40 would be an outlier, Ferdie brought in some clinical reasoning:

Ferdie: Whether this protein is 1.40 or 2.06 has no meaning whatsoever.

Petra: No, it is just too high.

Ferdie: But if it were 0.56 or 0.38 then it would be a huge difference. Because at 0.38 specialists would say: I am not going to give a treatment [a value below 0.50 means no risk of thrombosis]. With this one [0.56], they say: here you go, anticoagulation [drug against thrombosis].

Only correct reasoning was coded, and students' statements or reasoning led by the teacher or supervisor were not coded. One meeting was coded collaboratively, after which the first author coded the remaining fragments. He repeated the analysis of 90 fragments more than 7 months later. The intrarater reliability measured with Cohen's kappa was 0.86 , which is reasonably high.

To analyze whether the level of codes increased, we computed in SPSS the subsequent mean ranks, checked homogeneity of variance, used the Kruskal-Wallis test for testing the null hypothesis that the medians were the same and used the Jonckheere-Terpstra test for testing the presumed positive trend in these ordinal data. An effect size was also computed (Field, 2009).

\section{Results}

We first address qualitatively the question of how students learned to integrate statistical and work-related knowledge, and then quantitatively the question as to what extent they did so in our boundary-crossing approach. Last, we give an impression of how the students and their regular teacher appreciated the boundary-crossing approach.

\subsection{How students integrated statistical and work-related knowledge}

The first meeting was devoted to the question of what a method comparison could entail. None of the students had started their internship research on such a task. They mentioned several practical concerns such as time and resources, but no statistical techniques or concepts that are 
involved in method comparison. Their statistical knowledge turned out to be fragmentary and superficial. What they did mention was that "checks" should be carried out. By this, they meant stability of measurements, typically represented in control charts. When it came to the essence of comparing two machines, no student thought of correlation or regression. The teacher drew two axes and tried to evoke some discussion about correlation:

Teacher: Correlation, are you familiar with this?

Sylvana: Yes.

Teacher: Correlation coefficient?

Ferdie: Yes, that.

Sylvana: I think with that line.

Ferdie: Yeah, that's it.

Sylvana: I think it is something like this [drawing a straight line]. (...) The slope, right?

Ferdie: Yes, variation coefficient.

This fragment illustrates their inarticulate and superficial way of talking about statistics at the start of the intervention. Examples of reasoning were generally very pragmatic: "if the check deviates, then you can repeat the measurement" and "if it becomes too expensive, you could better outsource the measurements" (level 2 fragments). In other words, their perspective was generally work-related and practical. They showed awareness of some practical reasons but not of many theoretical reasons involved in method comparison.

The second meeting was devoted to supporting the students in taking a more statistical perspective on laboratory work. In particular, we addressed the concepts of precise (little variation) and accurate (correct arithmetic mean), and the graphical representation of control charts (see e.g., Hoyles, Bakker, Kent, \& Noss, 2007). We used software developed for operators (Bakker et al., 2009) to make students aware of the difference between target and average, and between control limits and specification limits. Ferdie was surprised that operators worked with limits of plus and minus three standard deviations whereas he had only seen two SD limits in his lab. He did understand that "If you are outside three SD, then your result is unreliable" (level 4 fragment). Sylvana assumed that "in a factory, it concerns materials so the limits may be wider, but in a laboratory it is about patients, so that is very important" (level 2). Moreover, it turned out that there was confusion about the names of such charts: What are the differences between control charts, SPC charts, and Shewhart and Levey Jennings chart? The teacher encouraged them to find out in their own laboratories which conventions and which charts were used. Moreover, students were asked to read the report of the previous year's student (intended as a boundary object) and to formulate questions to the supervisors who would visit the next meeting (to foster reflection).

In the third meeting, the students asked several questions about the report. One example concerned the use of outlier tests (Dixon's Q test or Grubbs' test), which students had learned at school. Having been asked by us about the use of such tests at work, the students reported that they were not used in their laboratories, and the supervisors present in the third meeting confirmed this. In regular practice, it was generally sufficient to use common sense: Causes of 
outliers were mostly rather obvious for those who had done the analysis, because they had seen something happen or knew what they had done wrong. By reflecting on the use of these statistical tests, the students became aware of perspectives taken in the laboratories.

One of the richest dilemmas raised in the third meeting was introduced by one supervisor. Assume a new machine, such as machine B in Fig. 1, is going to be used because it is reliable ( $R^{2}=0.9648$ is fine), faster, and cheaper than machine A, but systematically measuring lower than machine A. The slope of 0.751 suggests that the bias is about minus $25 \%$. What should the laboratory technicians decide? One option is to build in a correction factor (of $1 / 0.751=$ 1.33) into machine B's software so that measurement values are pretty much the same as before with machine A. Another option is to tell medical specialists that the values have gone down systematically. If a reference value of $0.5 \mathrm{mg} / \mathrm{L}$ of a particular substance (here, a specific protein) in blood used to be the critical value for checking a particular disease (here, thrombosis), the new reference value would become $0.7464 * 0.5=0.37 \mathrm{mg} / \mathrm{L}$.

Both options have advantages and disadvantages. In the first option, specialists do not have to get used to new reference values, but there is a risk in a reboot of the machine or installation of updated software that the correction factor is not carried over, or that users are not aware of a correction factor being built in. In the second option, specialists will become confused because they already have a sense of which concentrations of substances in blood are of clinical significance. If these values change because of one machine measuring differently, they will not be pleased. Moreover, comparison across laboratories or hospitals will become impossible. This example illustrates some of the considerations that can and should be made in laboratory work. In other words, there are multiple perspectives involved in making a decision.

As a final example from the third meeting, we mentioned that one of the workplace supervisors said they were satisfied with correlation coefficients of 0.9 for particular chemical substances. Because the students and teacher were surprised, the supervisors and teacher stimulated the students to find out what were the norms at their own laboratories.

In the fourth meeting, students reported back some of their findings; for example, Petra noted (from a level 3 fragment).

Petra: But there are things that are different in my lab. (...) They [the supervisors] said that a correlation of 0.9 was enough, but at my lab, they say 0.099 , uhm, 0.99 .

We also returned to the question of what was involved in a method comparison. In this meeting, the students showed a much richer knowledge of what could be involved, and which statistical techniques are relevant.

Between the fourth and fifth meetings, the students had started their own research projects. At the fifth meeting, they also had some preliminary data. The aforementioned dilemma arose again when the students were discussing Ferdie's data (represented, with some adjustments, in Fig. 1), because machine B measured systematically lower than machine A. This gave rise to interactions at level 4 because a mathematical perspective (e.g., correction factor) was integrated with a work-related perspective (on using a correction factor or for changing the reference value).

Sylvana: If you assume that this one [machine A] is reliable and this one [machine B] lower, then you can [interrupted]

Petra: build in a correction factor.

Ferdie: That would be possible but the point is that these are totally different measurements. 
Sylvana: But then you take reference values as your starting point.

Ferdie: I think you cannot just build that [correction factor] in.

Sylvana: Otherwise you would have to adjust that one [pointing to the reference value].

Such examples illustrate how the students had integrated statistical reasoning in their workrelated knowledge. Not only did they learn to use Excel ${ }^{\mathrm{TM}}$ in finding regression lines and correlation coefficients, but they also took into account the perspectives of the medical specialists. Compared to the earlier meetings, they could more easily combine multiple perspectives.

\subsection{To what extent did students integrate statistical and work-related knowledge?}

Table 2 provides the number of codes per meeting and level, and Fig. 2 shows the stacked percentages of knowledge integration levels per meeting. The mean ranks of the subsequent meetings increased from 77 in the first meeting, through 82, 95, 114, up to 134 in the last meeting. Analysis with the Kruskal-Wallis test suggests that it is extremely unlikely that these differences are by chance, $H(4)=32.87, p<0.001$. Results from the Jonckheere-Terpstra test indicate that we can assume a positive trend $(J=10438 ; z=5.50 ; p<0.001)$. The effect size $r(J)=z / \sqrt{ } N=5.5 / \sqrt{ } 201=0.39$, which can be considered medium. These results suggest that our aim of improving knowledge integration level was accomplished.

\subsection{Participants' perceptions of the boundary-crossing approach}

The students appreciated the approach and all claimed they had learned a lot. Ferdie and Petra expressed surprise about the statistics involved in his task, and about how this statistics in the end turned out to be practical. Sylvana said the following.

Sylvana: I think that, especially in the beginning, we thought more about the costs and those kinds of things, and the time. Yes, and now we think more about the statistics. That it is also fun that you know how it works in your own laboratory now. Normally you don't think of these things.

The supervisors were eager to come back, even though they were not paid to do so. One of them emphasized that there was so much more that she wanted to get across to the students.

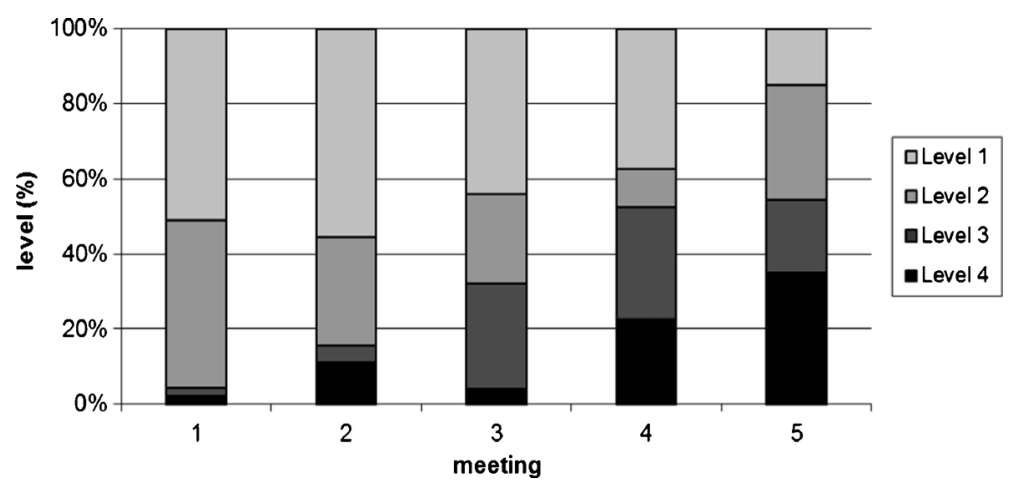

Fig. 2 Stacked percentages of knowledge integration levels during group interaction per meeting 
She saw it as her duty to educate a new generation of qualified laboratory technicians, of which a shortage was to be foreseen. The regular teacher was also very positive about the approach. After the third meeting, she exclaimed, "This is a feast. This is what it should be like." The following year, she tried to pay more attention to the statistics involved in student projects; to this end, she used examples from student reports, just as we had done the year before. An educational broadcasting company made a brief movie about the research in which a student, the regular teacher and researcher were interviewed (in Dutch): http://www.leraar24.nl/video/3499.

\section{Discussion}

The purpose of our research was to support students in integrating school-taught statistical knowledge with work-related knowledge. We stimulated boundary crossing in terms of reflection in the hope of propelling transformation, here, in the form of knowledge integration. Our boundary-crossing approach can be characterized by the following principles. The second and third can be seen as corollaries of the first:

1. Stimulating students to reflect (i.e., make and take perspectives), as the basis for transformation (i.e., hybridization) of their knowledge. We encouraged students to formulate questions, ask them in their workplaces, and report the answers back at school.

2. Involving teachers and students as well as workplace supervisors to support students in their efforts to integrate different types of knowledge (transformation). In our case, workplace supervisors visited a school meeting, when they answered well-prepared student questions and raised new dilemmas.

3. Using boundary objects. In our case, the central boundary object was a report by a student of a previous year. This choice had at least two benefits: (a) the workplace supervisors were familiar with it as they had supervised the method comparison reported; and (b) for the students, the report functioned as an example of what they were going to do, and how their work could be reported.

In this article, we asked how, and to what extent, students in our boundary-crossing approach learned to integrate statistical and work-related knowledge. Our qualitative analysis gives a sense of how the three students integrated school-taught statistical and work-related knowledge. In the final meeting, they showed a rather sophisticated understanding of workrelated dilemmas, also taking into account the perspective of medical specialists (an example of perspective taking). They showed awareness of the reasons for doing or not doing particular things such as building in a correction factor, using a particular measurement machine, or conducting a statistical test for outliers. We conceptualize their learning process as transformation (in the form of hybridization) as a consequence of reflection (taking multiple perspectives). The quantitative analysis shows that the improvement in the students' knowledge integration levels was statistically significant and with medium effect size. Moreover, students and their regular teacher were positive about the boundary-crossing approach.

There are some limitations to the study. First, it investigated only three students in a setting in which all three worked on a similar work project: method comparison of measurement machines. Though a fairly common task for laboratory technicians at MBO level, it is not the only work task involving statistics. Yet, the statistical techniques used in this task seem to be the most common ones for laboratory technicians in the Netherlands. Second, the first author had to teach because the regular teacher did not feel at ease with the statistics involved in 
method comparison. More teaching experiments with larger groups in different vocational areas and with the regular teachers are therefore desirable. Third, we had no control group to compare with, so we do not know how much of the students' improvement can be attributed to the intervention. However, the medium effect size and the content of students' reasoning suggest that the intervention had a major impact. We thus think that a boundary-crossing approach holds promise for vocational students such as those in this study.

We end with a few points of discussion. One issue that came up in our research is the distribution of knowledge. By reflecting on knowledge in practice, vocational students can also become aware of who of their fellow employees knows what, and who can help them with which questions. One interesting effect of inviting the workplace supervisors was that the supervisors started talking with the teachers about what was possible and desirable in the curriculum (perspective making and taking). They asked about the curriculum, the books used, and mentioned a desire for a regional meeting in which school and work could be better attuned (a quest for transformation). In other words, unplanned boundary crossing between supervisors and teachers was the result of the invitation to the third meeting.

A second point is that integration of different types of knowledge can be promoted in different ways. We have elaborated what we call a boundary-crossing approach, since it is inspired by the learning mechanisms found in the boundary-crossing literature. However, Hahn (2011) took a somewhat different approach, with a similar goal. It would be interesting to compare the different approaches at both theoretical and practical levels.

Third, our research contributes to the literature on vocational education but could also be relevant to general education, because context-based, project-based, and other authentic approaches are also explored in general education. For example, the vocational laboratory context formed the basis for one chapter of a unit for pre-university students as well as for an assessment item (Dierdorp, Bakker, Eijkelhof, \& van Maanen, 2011, 2013). Insight into how, more broadly, mathematics and statistics are used at work, and how vocational students can be prepared for this practical usage, is likely to be a useful resource for general education as well. We should keep in mind, however, that general educational students do not usually have the same knowledge of particular occupations as do vocational students. Yet, collaborative project work conducted with teachers of their practical subjects may be relevant.

Fourth, our study further points to the fact that many characterizations of school versus workplace knowledge are simplistic. In vocational education and workplace research, it is very common to use binary distinctions such as codified versus episodic knowledge (van der Sanden \& Teurlings, 2003), explicit versus implicit, and "uncontextualized" versus "contextual" (Tynjälä, 2008, p. 133). In contrast, our examples show that much of the workplace knowledge about method comparison is actually just as codified, explicit, and decontextualized as schooltaught statistics. It is more a matter of taking a different perspective: Whereas school-taught statistics is focused on calculation and interpretation of measures such as variation coefficient, correlation coefficient, and regression; workplace knowledge is concerned with stability, reproducibility, linearity, and so forth. However, what is crucial for the students we studied, and novice workers in general, is that they learn to integrate and enhance the different types of knowledge, so as to form an integrated whole needed to be able to take multiple perspectives.

There is a need for more nuanced conceptualizations of what such knowledge integration involves. We propose that Brandom's (2000) inferentialism may have something to offer here (cf. Guile, 2006). One concept from inferentialism that we consider especially useful is "web of reasons" (Brandom, 1994, p. 5). As we interpret it, this philosophical concept refers to the complex of interconnected reasons, premises and implications, motives for action and activity, and utility of tools for particular purposes that are at stake in particular situations (Bakker \& Derry, 2011). In the workplace, some of these reasons are practical, some are theoretical, and 
they are often weighed for their relative merits. Our analysis suggests that vocational students, interns, apprentices, and employees need to learn to reason with a web of different relevant reasons (practical, statistical, mathematical, etc.) based on different types of knowledge. Within such a web, we could analytically distinguish between reasons grounded on predominantly codified knowledge and those on episodic knowledge; we could indicate reasons made explicit and others left implicit (though perhaps historically once explicit); and we could characterize some reasons as predominantly situated and others as general. Future research involving fine-grained analyses of webs of reasons as well as their formations is therefore recommended for a more nuanced conceptualization of vocational and workplace knowledge, and learning processes in this interesting domain.

Acknowledgments We acknowledge funding by the Netherlands Organization for Scientific Research (NWO-PROO), under grant number 411-06-205. Thanks also to Xaviera van Mierlo for assisting in the data collection and to Bert Nijdam and Michiel Veldhuis for their statistical advice. We thank Gail FitzSimons for her insightful comments and corrections to earlier versions of this manuscript.

Open Access This article is distributed under the terms of the Creative Commons Attribution License which permits any use, distribution, and reproduction in any medium, provided the original author(s) and the source are credited.

\section{References}

Akkerman, S. F., \& Bakker, A. (2011). Boundary crossing and boundary objects. Review of Educational Research, 81, 132-169.

Akkerman, S. F., \& Bakker, A. (2012). Crossing boundaries between school and work during apprenticeships. Vocations \& Learning, 5, 153-173.

Bakker, A., \& Akkerman, S. F. (2013). Leren door boundary crossing tussen school en werk [Learning through boundary crossing between school and work]. Submitted to Pedagogische Studiën.

Bakker, A., \& Derry, J. (2011). Lessons from inferentialism for statistics education. Mathematical Thinking and Learning, 13, 5-26.

Bakker, A., Groenveld, D. J. G., Wijers, M., Akkerman, S. F., \& Gravemeijer, K. P. E. (2012). Proportional reasoning in the laboratory: An intervention study in vocational education. Educational Studies in Mathematics. Online doi:10.1007/s10649-012-9393-y.

Bakker, A., Kent, P., Derry, J., Noss, R., \& Hoyles, C. (2008). Statistical inference at work: The case of statistical process control. Statistics Education Research Journal, 7(2), 130-145.

Bakker, A., Kent, P., Hoyles, C., \& Noss, R. (2011). Designing for communication at work: A case for technology-enhanced boundary objects. International Journal of Educational Research, 50(1), 26-32.

Bakker, A., Kent, P., Noss, R., \& Hoyles, C. (2009). Alternative representations of statistical measures in computer tools to promote communication between employees in automotive manufacturing. Technology Innovations in Statistics Education, 3(2). Retrieved from: http:/www.escholarship.org/uc/item/53b9122r.

Bakker, A., Wijers, M., \& Akkerman, S. F. (2010). The influence of technology on what vocational students need to learn about statistics: The case of lab technicians. In C. Reading (Ed.), Data and context in statistics education: Towards an evidence-based society. Proceedings of the Eighth International Conference on Teaching Statistics (6 pp.). Voorburg: International Statistical Institute. http://www.stat.auckland.ac.nz/ iase/ publications/icots8/ICOTS8_8I4_BAKKER.pdf.

Bakker, A., Wijers, M., Jonker, V., \& Akkerman, S. F. (2011). The use, nature and purposes of measurement in intermediate-level occupations. ZDM The International Journal on Mathematics Education, 43(5), 737-746.

Boland, R. J., \& Tenkasi, R. V. (1995). Perspective making and perspective taking in communities of knowing. Organization Science, 6, 350-372.

Brandom, R. (1994). Making it explicit. Reasoning, representing, and discursive commitment. Cambridge, MA: Harvard University Press.

Brandom, R. (2000). Articulating reasons: An introduction to inferentialism. Cambridge, MA: Harvard University Press. 
Dierdorp, A., Bakker, A., Eijkelhof, H. M. C., \& van Maanen, J. A. (2011). Authentic practices as contexts for learning to draw inferences beyond correlated data. Mathematical Thinking and Learning, 13, 132-151. doi: 10.1080/10986065.2011.538294.

Dierdorp, A., Bakker, A., Eijkelhof, H. M. C., \& van Maanen, J. A. (2013). Betekenisvolle statistiek in beroepspraktijken als brug tussen wiskunde en natuurwetenschappen: Evaluatie van een ontwerponderzoek. [Meaningful statistics in professional practices as a bridge between mathematics and science.]. Pedagogische Studien, 90, 4-18.

Engeström, Y., Engeström, R., \& Kärkkäinen, M. (1995). Polycontextuality and boundary crossing in expert cognition: Learning and problem solving in complex work activities. Learning and Instruction, 5, 319-336.

Field, A. (2009). Discovering statistics using SPSS (2nd ed.). London: Sage.

FitzSimons, G. E., \& Coben, D. (2009). Adult numeracy for work and life: Curriculum and teaching implications of recent research. In R. Maclean \& D. Wilson (Eds.), UNESCO-UNEVOC International handbook of technical and vocational education and training. Bridging academic and vocational education, vol. 6 (pp. 2731-2745). Dordrecht: Springer.

Guile, D. (2006). Learning across contexts. Educational Philosophy and Theory, 38, 251-268.

Hahn, C. (2011). Linking academic knowledge and professional experience in using statistics: A design experiment for business school students. Educational Studies in Mathematics. Online doi:10.1007/s10649012-9393-y first.

Hoyles, C., Bakker, A., Kent, P., \& Noss, R. (2007). Attributing meanings to representations of data: The case of statistical process control. Mathematical Thinking and Learning, 9, 331-360.

Hoyles, C., Noss, R., Kent, P., \& Bakker, A. (2010). Improving mathematics at work: The need for technomathematical literacies. London: Routledge.

Kent, P., Noss, R., Guile, D., Hoyles, C., \& Bakker, A. (2007). Characterizing the use of mathematical knowledge in boundary-crossing situations at work. Mind, Culture, and Activity, 14, 64-82. doi:10.1080/ 10749030701307747.

Lave, J. (1988). Cognition in practice: Mind, mathematics and culture in everyday life. Cambridge, MA: Cambridge University Press.

Meeus, W., Van Petegem, P., \& Van Looy, L. (2006). Portfolios in higher education: Time for a clarificatory framework. International Journal of Teaching and Learning in Higher Education, 17, 127-135.

Nunes, T. A., Schliemann, D., \& Carraher, D. W. (1993). Street mathematics and school mathematics. Cambridge, UK: Cambridge University Press.

Raadschelders, H. M., \& den Rooijen, M. F. M. (2007). Kwaliteitszorg en statistiek in het laboratorium [Quality assurance and statistics in the laboratory]. Arnhem, the Netherlands: Syntax Media.

Reading, C., \& Reid, J. (2004). An emerging hierarchy of reasoning about distribution: From a variation perspective. Statistics Education Research Journal, 5(2), 46-68, http://www.stat.auckland.ac.nz/serj.

Roth, W.-M. (2012). Rules of bending, bending the rules: The geometry of conduit bending in college and workplace. Educational Studies in Mathematics. doi: 10.1007/s10649-011-9376-4

Star, S. L., \& Griesemer, J. R. (1989). Institutional ecology, translations and boundary objects: Amateurs and professionals in Berkeley's Museum of Vertebrate Zoology, 1907-39. Social Studies of Science, 19, 387-420.

Suchman, L. (1994). Working relations of technology production and use. Computer Supported Cooperative Work, 2, 21-39.

Tuomi-Gröhn, T., \& Engeström, Y. (2003). Conceptualizing transfer: From standard notions to developmental perspectives. In T. Tuomi-Gröhn \& Y. Engeström (Eds.), Between school and work. New perspectives on transfer and boundary-crossing (pp. 19-38). Amsterdam: Pergamon.

Tynjälä, P. (2008). Perspectives into learning at the workplace. Educational Research Review, 3, 130-154.

van der Sanden, J. M. M., \& Teurlings, C. C. J. (2003). Developing competence during practice periods: The learner's perspective. In T. Tuomi-Gröhn \& Y. Engeström (Eds.), School and work: New perspectives on transfer and boundary-crossing (pp. 119-138). Amsterdam: Pergamon.

Watson, J., \& Moritz, J. (2000). Developing concepts of sampling. Journal for Research in Mathematics Education, 31, 44-70.

Wedege, T. (1999). To know — or not to know - mathematics, that is a question of context. Educational Studies in Mathematics, 39, 205-227.

Wenger, E. (1998). Communities of practice: Learning, meaning, and identity. Cambridge: Cambridge University Press.

Williams, J. S., \& Wake, G. D. (2007). Metaphors and models in translation between college and workplace mathematics. Educational Studies in Mathematics, 64, 345-371. 